\title{
Peningkatan Kualitas Minuman Sari Lidah Buaya pada Usaha Muztaqbalah Malang
}

\section{(Improving the Quality of Aloe Vera Drink at Muztaqbalah Malang Business)}

\author{
Ikhlasul Amallynda ${ }^{1}$, Annisa Kesy Garside ${ }^{2 *}$, Nadia Mardiyah ${ }^{3}$ \\ ${ }^{1,2}$ Teknik Industri, Fakultas Teknik, Universitas Muhammadiyah Malang - \\ Jalan Raya Tlogomas No. 246 Malang \\ ${ }^{3}$ Ilmu dan Teknologi Pangan, Fakultas Pertanian dan Peternakan, Universitas Muhammadiyah Malang - \\ Jalan Raya Tlogomas No. 246 Malang
}

\begin{tabular}{|c|c|}
\hline ARTICLE INFO & ABSTRAK \\
\hline $\begin{array}{l}\text { Article history } \\
\text { Received : } 10 \text { April } 2021 \\
\text { Revised : } 25 \text { Mei } 2021 \\
\text { Accepted : } 08 \text { Juni } 2021 \\
\text { DOI : } \\
\text { https://doi.org/10.33366/jast.v5i1 } \\
.2351 \\
\text { Keywords : aloe vera extract; } \\
\text { beverage; preservative additive; } \\
\text { shelf life. } \\
\text { *e-mail corresponding author : }\end{array}$ & $\begin{array}{l}\text { Usaha Muztaqbalah merupakan usaha kecil pembuat minuman sari lidah buaya } \\
\text { yang terletak di Jetis, Dau, Kabupaten Malang. Permasalahan yang dihadapi oleh } \\
\text { UKM adalah umur simpan produk minuman sari lidah buaya belum bertahan lama } \\
\text { meski sudah ditambahkan bahan natrium benzoat. Selain itu konsumen } \\
\text { menginginkan rasa yang lebih segar pada minuman sari lidah buaya. Berdasarkan } \\
\text { permasalahan yang dihadapi oleh usaha Muztaqbalah, maka tujuan program } \\
\text { pengabdian ini adalah membantu pemilik usaha untuk meningkatkan kualitas } \\
\text { minuman sari lidah buaya. Setelah melakukan konsultasi dan pendampingan } \\
\text { diusulkan penambahan tahapan dalam proses pembuatan yaitu perendaman dengan } \\
\text { air garam, penyaringan sebelum daging lidah buaya diblender dan sterilisasi } \\
\text { kemasan botol atau cup sebelum pengemasan. Berdasarkan hasil analisis Total Plate } \\
\text { Count (TPC) maka bahan tambahan pengawet yang diusulkan adalah asam sitrat } \\
\text { karena memiliki umur simpan yang lebih lama dibanding jeruk nipis. }\end{array}$ \\
\hline
\end{tabular}

\section{PENERBIT}

\section{UNITRI PRESS}

J1. Telagawarna, TlogomasMalang, 65144, Telp/Fax: $0341-565500$

\section{ABSTRACT}

Muztaqbalah is a small business located in Jetis, Dau, Malang Regency that manufactures aloe vera extract beverages. The problem faced by Small and Medium Enterprises (SME) is that the shelf life of aloe vera products is short, although sodium benzoate has been added. In addition, consumers want a fresher taste in aloe vera extract beverages. Based on the problems faced by Muztaqbalah's business, this program aims to help business owners improve the quality of aloe vera extract beverages. After consulting and mentoring, it is suggested to add additional stages in the manufacturing process, soaking in saltwater, filtering before the aloe vera meat is blended, and sterilizing bottles or cups before packaging. Based on the results of the Total Plate Count (TPC) analysis, the proposed preservative additive is citric acid because it has a longer shelf life than lime.
Cara Mengutip : Amallynda, I., Garside, A.K., Mardiyah, N. (2021). Peningkatan Kualitas Minuman Sari Lidah Buaya pada Usaha Muztaqbalah Malang. JAST: Jurnal Aplikasi Sains dan Teknologi, 5(1), 44-52. doi:https://doi.org/10.33366/jast.v5i1.2351 


\section{PENDAHULUAN}

Usaha Muztaqbalah terletak di Jetis, Dau, Kabupaten Malang. Pemilik memulai usaha dengan membuat produk olahan lidah buaya pada tahun 2018 dan memasarkan melalui pameran-pameran, toko online yang dimilikinya, dan pemasaran mulut ke mulut. Saat ini wilayah pemasaran masih terbatas di kota Malang dan kabupaten, sedangkan segmen yang ditargetkan untuk membeli produk mulai dari bayi sampai lansia. Gambar 1 menunjukkan foto produk yang dihasilkan. Saat ini minuman lidah buaya dijual dalam kemasan botol dan cup.

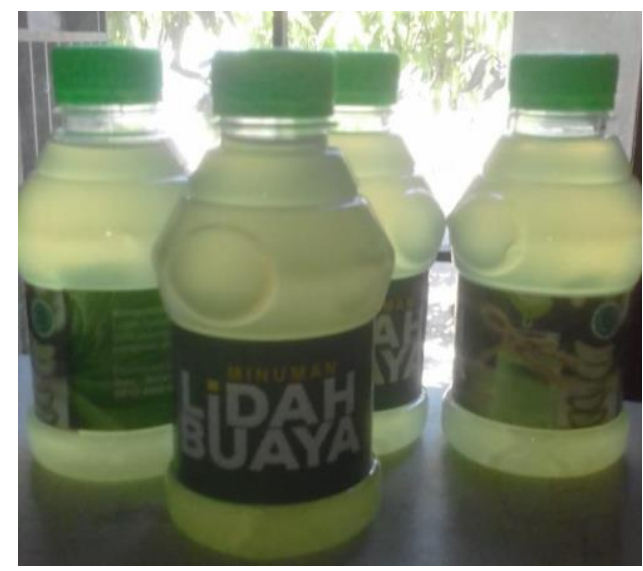

Gambar 1. Produk minuman sari lidah buaya

Dari aspek produksi, pembuatan minuman lidah buaya dimulai dengan mengambil daging lidah buaya kemudian diblender. Setelah itu hasil blenderan disaring sehingga diperoleh sarinya. Selanjutnya sari lidah buaya, gula singkong dan pengawet yaitu natrium benzoat dimasukkan ke air yang mendidih dan direbus hingga matang. Setelah dingin, minuman lidah buaya siap dikemas. Dalam penambahan bahan pengawet, pemilik belum menemukan kombinasi bahan yang tepat sehingga masih coba-coba untuk mendapatkan umur simpan yang cukup lama dan rasa yang disukai oleh konsumen

Berdasarkan hasil diskusi antara mitra dengan tim pengabdian, diperoleh permasalahan mitra yang menjadi prioritas dan disepakati untuk diselesaikan dengan bantuan pihak tim pengabdian adalah bagaimana meningkatkan kualitas produk minuman sari lidah buaya.

\section{METODE KEGIATAN}

Teknik yang digunakan untuk menyelesaikan persoalan yang menjadi kesepakatan bersama adalah:

1. Konsultasi mengenai beberapa cara untuk meningkatkan kualitas produk dari segi proses pembuatan dan alternatif-alternatif Bahan Tambahan Pengawet (BTP) yang dapat digunakan. Tim pengabdian mengusulkan beberapa alternatif BTP berdasarkan penelitianpenelitian terdahulu yang telah dilakukan oleh Erwan dkk. [1] yang menggunakan natrium 
benzoat, sari lemon oleh Geri dkk. [2], asam sitrat oleh Ismiyati dkk. [3], dan jeruk nipis oleh Iryandi dkk. [4].

2. Pendampingan dalam perbaikan proses pembuatan minuman sari lidah buaya. Dalam pendampingan ini, tim pengabdian dibantu oleh mahasiswa dari jurusan Ilmu dan Teknologi Pangan (ITP) Universitas Muhammadiyah Malang.

3. Pendampingan dalam penentuan bahan tambahan pengawet. Tahap pertama, tim pengabdian akan mengusulkan beberapa jenis dan komposisi BTP. Selanjutnya pada tahap kedua, tim Pengabdian dan pemilik akan melakukan uji rasa untuk memilih beberapa alternatif Bahan Tambahan Pengawet (BTP) yang menghasilkan minuman sari lidah buaya yang lebih enak dan segar. Pada tahap ketiga, analisis masa simpan dengan Total Plate Count (TPC) dilakukan untuk mengetahui umur simpan minuman sari lidah buaya yang paling aman.

\section{KARYA UTAMA}

Karya utama kegiatan pengabdian ini adalah usulan perbaikan proses pembuatan untuk minuman sari lidah buaya dan bahan tambahan pengawet yang harus digunakan oleh pemilik UKM. Gambar 2 menunjukkan proses pembuatan dan komposisi bahan tambahan pengawet pada minuman sari lidah buaya yang digunakan oleh UKM saat ini. Sedangkan gambar 3 menunjukkan proses pembuatan dan komposisi bahan tambahan pengawet pada minuman sari lidah buaya yang diusulkan.

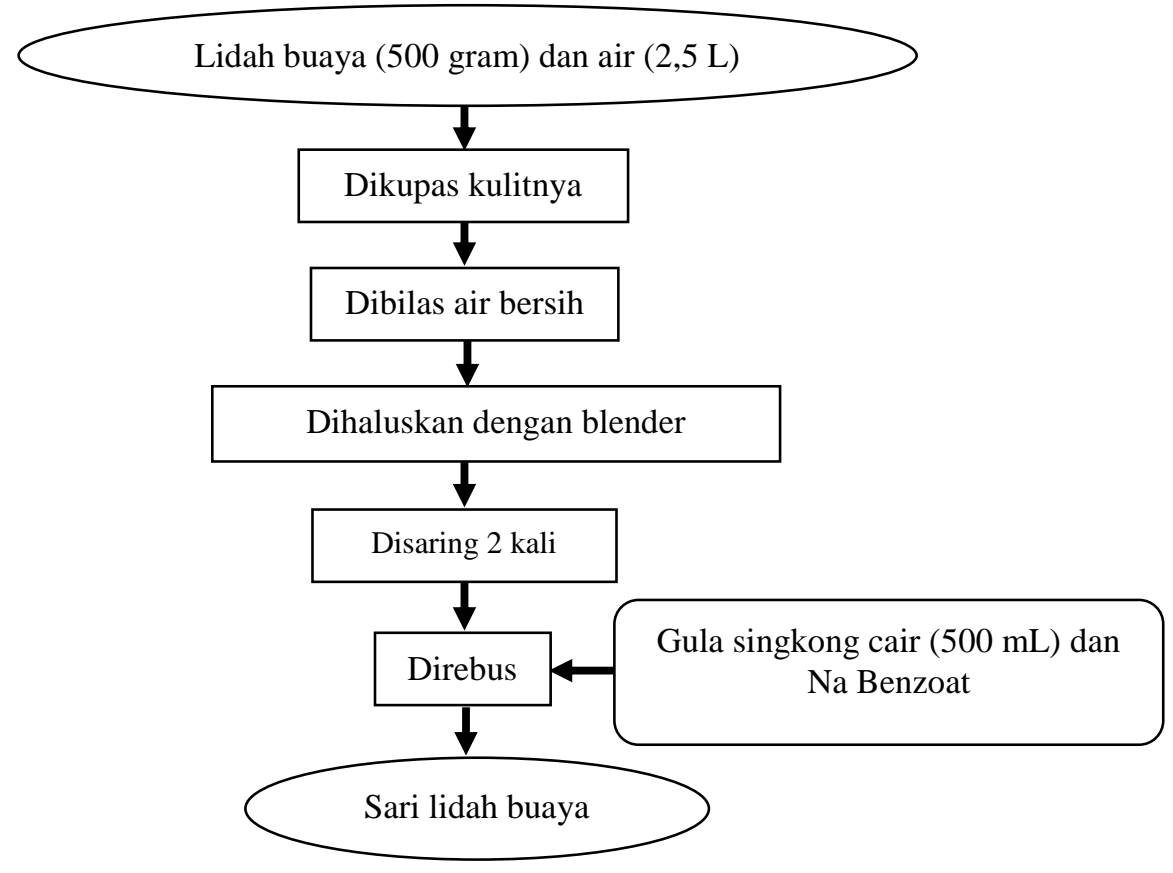

Gambar 2. Metode pengolahan dan komposisi bahan pada kondisi awal 


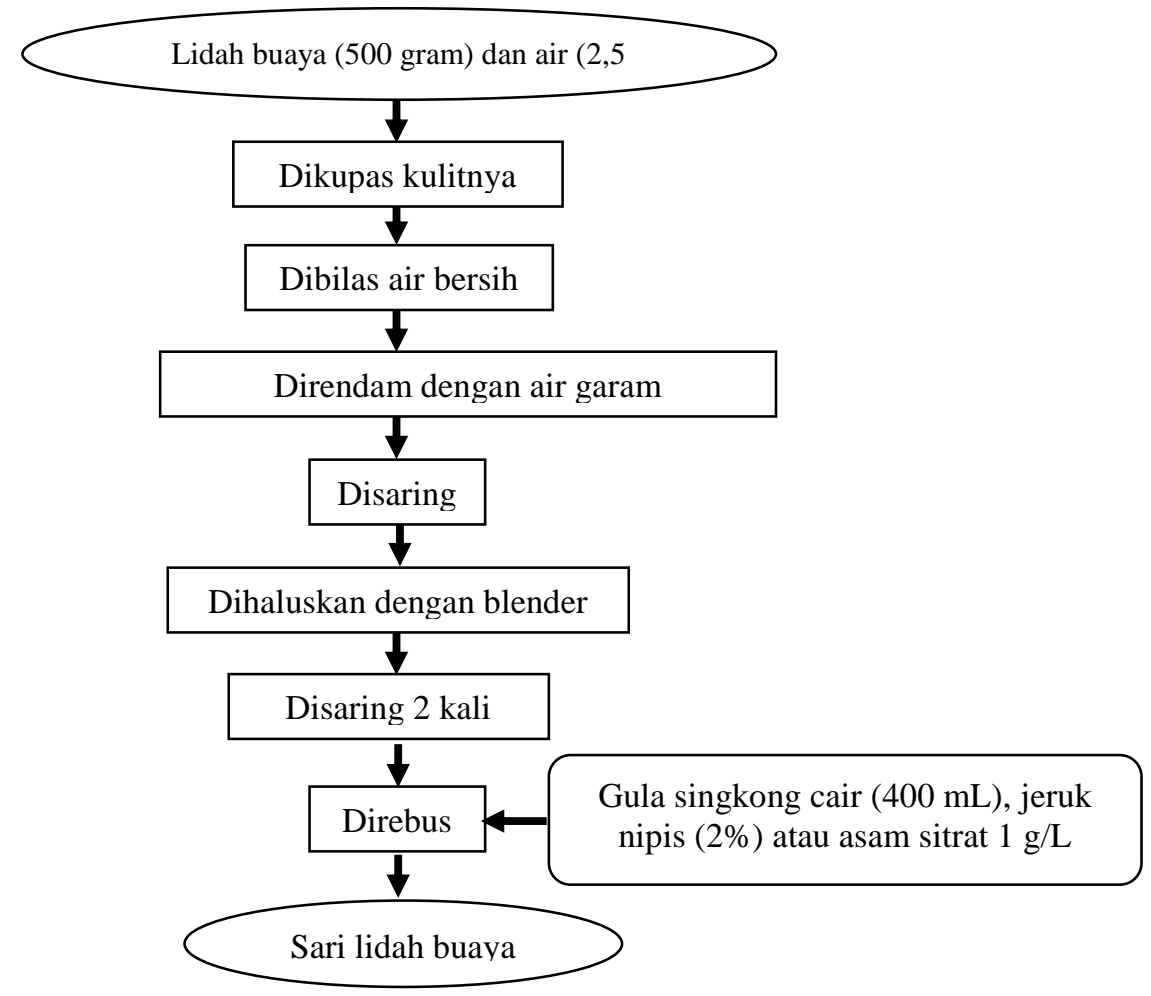

Gambar 3. Metode pengolahan dan komposisi bahan pada kondisi usulan

\section{ULASAN KARYA}

Usulan proses pembuatan dan komposisi bahan tambahan pengawet diperoleh melalui 3 kali percobaan. Pada percobaan pertama, menggunakan tahapan proses yang digunakan saat ini dan bahan tambahan pengawet yang diusulkan adalah : bubuk kayu manis, jeruk nipis, asam sitrat dan natrium benzoat.

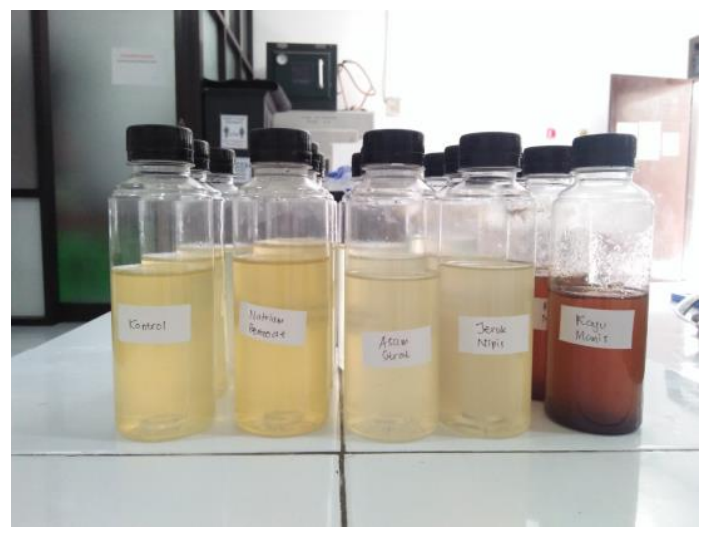

Gambar 4. Hasil percobaan ke-1 pembuatan minuman sari lidah buaya

Panelis yang terdiri dari pihak UKM dan Tim Pengabdi lebih menyukai sari lidah buaya dengan penambahan asam sitrat dan jeruk nipis karena tampilan lebih jernih dan rasa lebih segar. 
Tim pengabdi bersama dengan mahasiswa ITP UMM melakukan review literatur pada beberapa penelitian terdahulu yang terkait dengan pembuatan minuman sari lidah buaya. Menurut Putty dalam Sari [5] pemberian garam sebanyak 2,5\% pada pembuatan sari lidah buaya bertujuan untuk mengeluarkan sisa lendir yang masih tertinggal dan mengurangi rasa getir dan pahit. Hal ini sejalan juga dengan kegiatan pengabdian yang dilakukan oleh Rusanti dkk. [6]. Karena pihak UKM belum melakukan kegiatan ini maka Tim pengabdi menyarankan untuk dilakukan. Selain itu kegiatan penyaringan sebelum penghalusan lidah buaya perlu ditambahkan agar tampilannya lebih jernih lagi.

Pada percobaan kedua, pembuatan sari lidah buaya dilakukan berdasarkan usulan pada gambar 3. Hasil yang diperoleh telah sesuai dengan harapan. Selanjutnya dilakukan percobaan ketiga dengan tujuan untuk melakukan analisis masa simpan dengan analisis Total Plate Count (TPC). Langkah-langkah yang dilakukan dalam analisis TPC dimodifikasi dari penelitian yang telah dilakukan oleh Yunita, dkk. [7].

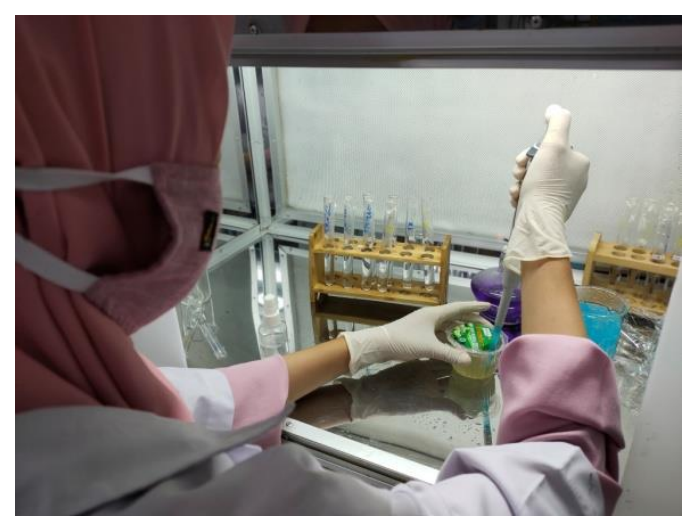

Gambar 5. Pengambilan sampel

Dokumentasi kegiatan yang dilaksanakan selama analisis Total Plate Count dapat dilihat pada gambar 5 dan 6. Dari hasil pengamatan tumbuhnya bakteri pada sampel minuman sari lidah buaya selama 3 minggu maka dilakukan perhitungan jumlah mikroba yang tumbuh dengan alat Colony Counter. Perhitungan dilakukan pada hari Ke-0, ke-7, ke14, dan ke-21. Hasilnya seperti ditunjukkan pada tabel 1.

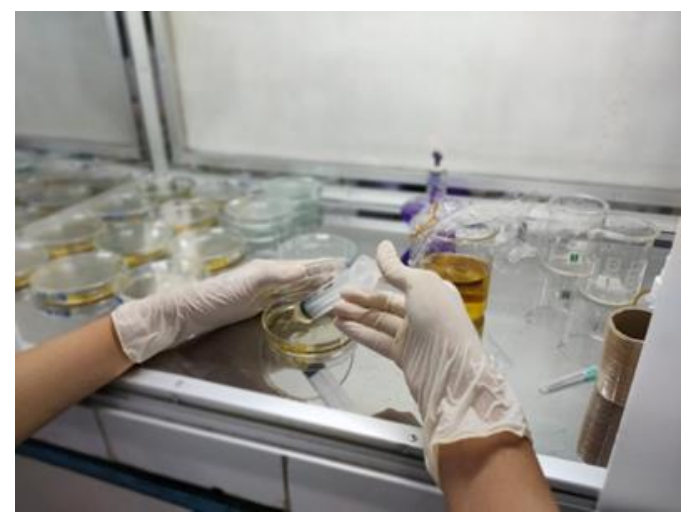

Gambar 6. Memasukkan media nutrient agar ke dalam petridish 
Tabel 1. Hasil Perhitungan Mikroba pada Penyimpanan Hari Ke-21

\begin{tabular}{cccc}
\hline BTP & Suhu & $\begin{array}{c}\text { Jumlah } \\
\text { Bakteri }\end{array}$ & Status \\
\hline Jeruk nipis & Ruang & TBUD & Tidak Aman \\
Asam sitrat & Ruang & $112 \times 10^{4}$ & Mengkhawatirkan \\
Jeruk nipis & Dingin & $8 \times 10^{1}$ & Aman \\
Asam sitrat & Dingin & $1 \times 10^{2}$ & Aman \\
\hline \multicolumn{4}{r}{ *TBUD = Terlalu banyak untuk dihitung }
\end{tabular}

Menurut SNI 3719:2014 [8] tentang sari buah, dinyatakan bahwa batasan maksimum cemaran mikroba dalam angka lempeng total (total plate count) yang adalah $1 \times 10^{4}$ koloni/g. Ketika sampel terhitung memiliki mikroba di bawah batas maksimum, maka sampel masih layak simpan dan konsumsi. Namun, jika sampel terhitung memiliki mikroba di atas jumlah maksium yang diijinkan, maka sampel tidak layak konsumsi. Dari tabel 1 dapat disimpulkan bahwa penggunaan bahan tambahan pengawet (BTP) jeruk nipis sudah tidak aman digunakan setelah seminggu. Sedangkan penggunaan BTP asam sitrat masih aman disimpan sampai 2 minggu pada suhu ruang dan 3 minggu pada suhu dingin (dalam kulkas). Dari hasil pengamatan selama 3 minggu maka faktor-faktor yang mempengaruhi umur simpan sari lidah buaya sebagai berikut:

1. Proses fermentasi sari lidah buaya dapat dipengaruhi oleh aktivitas mikrobia selama penyimpanan. Fermentasi spontan dari produk diawali dengan terbentuknya gula sederhana, selanjutnya gula diubah menjadi asam laktat oleh aktivitas bakteri asam laktat. Hasil analisis Total Plate Count bakteri yang semakin naik dengan semakin lama penyimpanan [9].

2. Proses degradasi substrat oleh yeast atau bakteri asam laktat. Reaksi ini akan menurunkan $\mathrm{pH}$ minuman sehingga menyebabkan terjadinya perubahan bau maupun rasa pada minuman sari lidah buaya [9].

3. Penyimpanan dilakukan di tempat yang dingin, kering, dan tidak terkena sinar matahari langsung. Penggunaan asam sitrat sebagai pengawet padat mempertahankan sari lidah buaya selama 2-3 bulan jika disimpan dalam lemari pendingin. Hal ini dikarenakan, pengawet memiliki berfungsi untuk mencegah kebusukan dan suhu yang rendah dapat meminimalisir aktivitas mikrobia [3].

4. Pasteurisasi dapat memperpanjang masa simpan dengan melakukan sterilisasi kemasan. Pasteurisasi sari lidah buaya yang dilakukan pada suhu $65{ }^{\circ} \mathrm{C}$ selama 30 menit dapat membunuh mikroba vegetative tertentu [3].

\section{DAMPAK DAN MANFAAT KEGIATAN}

Saat ini pemilik usaha Muztaqbalah masih trial error dalam menentukan kadar natrium benzoat sebagai bahan pengawet. Sehingga rasa minuman sari lidah buaya masih kurang segar dan penampakan produk kadang-kadang kurang jernih. Hal ini disebabkan 
daging lidah buaya memiliki rasa hambar dan aroma langu karena adanya senyawa aloin pada lendir daging lidah buaya. Oleh karena itu, perlu upaya mengurangi rasa hambar dan aroma langu daging lidah buaya dalam pembuatan minuman [2]. Menurut Sarwono [10], jeruk nipis dan sari lemon memiliki rasa asam, akan tetapi karena aromanya yang sedap, harum, dan memiliki aroma yang khas sehingga sering digunakan sebagai bahan untuk menghilangkan bau langu pada produk minuman Hal ini sejalan dengan penelitian Iryandi dkk. [4] yang menyatakan bahwa air jeruk nipis dapat menghilangkan aroma langu pada produk nata de soya. Selain itu kandungan asam sitrat yang terdapat pada jeruk nipis dapat berperan juga sebagai pengawet alami.

Berdasarkan hasil analisis umur simpan, usulan penggunaan bahan pengawet alami yaitu jeruk nipis memang masih kurang memuaskan karena produk sudah tidak aman digunakan pada suhu kamar pada hari ke-21. Demikian pula dengan usulan penggunaan bahan pengawet berupa asam sitrat. Dari hasil diskusi antara tim pengabdian dengan pemilik UKM maka usulan bahan tambahan pengawet yang akan digunakan adalah asam sitrat. Untuk memperpanjang umur simpan produk maka tim pengabdi menambahkan satu usulan yaitu mensterilkan kemasan botol atau cup sebelum pengemasan. Sehingga manfaat dari kegiatan pengabdian ini adalah memberikan usulan bahan tambahan pengawet yang lebih baik digunakan oleh pihak UKM.

Usulan lain yang diberikan penambahan tahapan dalam proses pembuatan yaitu perendaman dengan air garam dengan tujuan mengurangi rasa getir dan pahit. Selain itu menambah penyaringan sebelum daging lidah buaya diblender sehingga kegiatan penyaringan dilaksanakan dua kali. Berdasarkan usulan penambahan proses dan bahan tambahan pengawet maka contoh minuman sari lidah buaya dari hasil pendampingan seperti ditunjukkan pada gambar 7 .

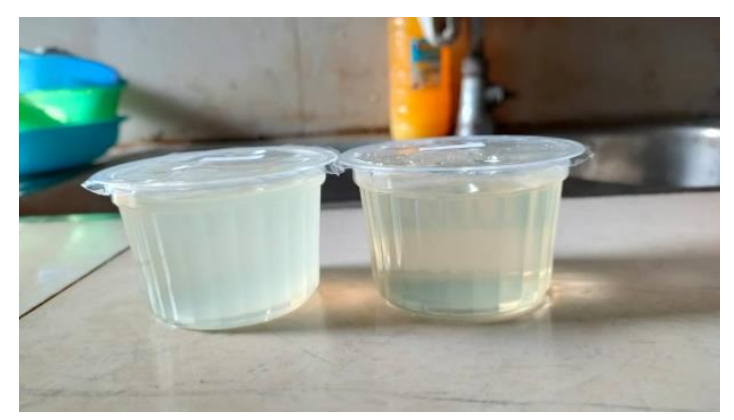

Gambar 7. Minuman sari lidah buaya dari hasil pendampingan

Berdasarkan testimoni beberapa konsumen yang membeli produk setelah kegiatan pendampingan ini selesai, sebagian besar mereka menyatakan bahwa minuman sari lidah buaya yang sekarang rasanya lebih segar dengan rasa manis asam yang pas. Sehingga diharapkan dampak kedepan setelah kegiatan pengabdian ini selesai adalah peningkatan penjualan karena minuman sari lidah buaya yang diproduksi sekarang memiliki kualitas yang lebih baik. Produk minuman sari lidah buaya lebih disukai konsumen dengan umur simpan kurang lebih satu bulan jika disimpan pada suhu kamar. 


\section{KESIMPULAN}

Kegiatan pengabdian dalam bentuk konsultasi dan pendampingan pembuatan minuman sari lidah buaya berjalan sesuai rencana yang telah dibuat. Dari hasil konsultasi dan pendampingan diusulkan bahan tambahan pengawet yang akan digunakan adalah asam sitrat, mensterilkan kemasan botol atau cup sebelum pengemasan, perendaman dengan air garam dengan tujuan mengurangi rasa getir dan pahit, dan penyaringan sebelum daging lidah buaya diblender sehingga kegiatan penyaringan dilaksanakan dua kali. Setelah dilaksanakan kegiatan pengabdian ini, minuman sari lidah buaya yang dihasilkan memiliki rasa lebih segar sehingga lebih disukai konsumen. Selain itu dari hasil analisis TPC diperoleh umur simpan produk kurang lebih satu bulan. Sehingga tujuan kegiatan pengabdian ini untuk meningkatkan kualitas minuman sari lidah buaya yang dihasilkan Usaha Muztaqbalah telah berhasil.

\section{PENGHARGAAN}

Ucapan terimakasih kepada Universitas Muhammadiyah Malang yang memberikan dukungan dalam pelaksanaan pengabdian kepada masyarakat ini.

\section{DAFTAR PUSTAKA}

[1] C. Erwan, N. Rahman, and C. E. W. Anggara, "Pembuatan Minuman Herbal Lidah Buaya (Alloevera) di Usaha Kecil Mikro Sari Kumetap Kabupaten Subang," in Prosiding SNaPP2016 Sains dan Teknologi, 2019, pp. 66-70.

[2] J. D. Geri, D. F. Ayu, and N. Harun, "Kombinasi Minuman Lidah Buaya Berkarbonasi dengan Sari Lemon Combination of Carbonated Aloe Vera Drink with Lemon Juice Jefrianta Demu Geri 1, Dewi Fortuna Ayu," J. Agroindustri Halal, vol. 5, no. 2, pp. 132-140, 2019.

[3] Ismiyati, R. A. Nugrahani, and T. Y. Hendrawati, "Diversifikasi Menjadi Produk Selai dan Peningkatan Mutu Jus Aloe Vera di SIGMA Food Sawangan Depok," J. Pengabdi. Kpd. Masy., vol. 3, no. 2, pp. 188-195, 2018.

[4] A. F. Iryandi, Y. Hendrawan, and N. Komar, "Pengaruh Penambahan Air Jeruk Nipis (Citrus aurantifolia) dan Lama Fermentasi Terhadap Karakteristik Nata De Soya," J. Bioproses Komod. Trop., vol. 1, no. 1, pp. 8-15, 2014.

[5] R. Sari, "Pengaruh Konsentrasi Gula Dan Suhu Pengeringan Terhadap Karakteristik Jelly Instan Lidah Buaya Instan (Aloa Vera),” Universitas Pasundan, 2016.

[6] W. D. Rusanti, A. M. Rani, A. M. Sari, D. Sunardi, and Yustinah, "Pelatihan Peningkatan Produk Makanan dan Kesejahteraan Masyarakat Melalui Pengembangan Produk Berbahan Dasar Aloevera Cileungsi Kidul, Bogor, Jawa Barat," in Prosiding Seminar Nasional Pengabdian Masyarakat LPPM UMJ, 2019, pp. 1-5. 
[7] M. Yunita, Y. Hendrawan, and R. Yulianingsih, "Analisis Kuantitatif Mikrobiologi Pada Makanan Penerbangan (Aerofood ACS) Garuda Indonesia Berdasarkan TPC (Total Plate Count) Dengan Metode Pour Plate," J. Keteknikan Pertan. Trop. dan Biosist., vol. 3, no. 3, pp. 237-248, 2015.

[8] Badan Standarisasi Nasional, Standar Nasional Indonesia Minuman Sari Buah. Jakarta, 2014.

[9] C. Wariyah, Riyanto, and M. Salwandri, "Kondisi Kritis dan Stabilitas Aktivitas Antioksidatif Minuman Gel Lidah Buaya (Aloe vera var. chinensis) selama Penyimpanan," Agritech, vol. 34, no. 2, pp. 113-119, 2014.

[10] B. Sarwono, Jeruk Nipis dan Pemanfaatannya. Jakarta: Gramedia Pustaka Utama, 1995. 